\title{
TETUÁN EN DOS GRABADOS DEL SIGLO XVIII
}

\author{
Enrique Gozalbes Cravioto*
}

No es precisamente Tetuán una ciudad que posea muchas y buenas representaciones gráficas de su paisaje urbano anteriores al siglo XX. Prácticamente, en lo que se conoce, las visiones de la ciudad, y en buena parte la cartografía acerca de la misma, dieron comienzo con la guerra hispano-marroquí de 1860, tal y como reflejó en su día Alfonso Sierra ${ }^{1}$. Por ejemplo, la ciudad no aparece en el siglo XVI, en el Civitates Orbis Terrarum, al contrario que Tánger, Ceuta o la bahía del Peñón de Vélez de la Gomera. En este caso la explicación se encuentra en que no era una plaza ocupada por los cristianos. Esta obra sí representa en color una imagen bastante detallada de la Ceuta portuguesa, por lo general bastante bien conocida, y su perspectiva al otro lado del arco de la bahía Sur no llega siquiera al cabo Negro, que da entrada a la ensenada de Tetuán; aparecen algunas torres de alquería, dos de ellas en roquedades en línea de mar, la mayor y más alejada sin duda en Castillejos, terminando la vista en la zona del Negrón².

Pese a este vacío hemos rastreado algunas imágenes de Tetuán en obras de periodos anteriores a la guerra de 1860, obteniendo algunos resultados que incorporaremos a la presente publicación. El Tetuán de los siglos XVIII y XIX que aparece representado es el que evoluciona desde la vieja ciudad morisca, de la que nos hablan las distintas fuentes, los viajeros y los padres redentores de cautivos $^{3}$, y entra ya en las percepciones y visiones del romanticismo, con

\footnotetext{
* Universidad de Castilla-La Mancha.

1. A. Sierra OchoA, El plano de la ciudad de Tetuán, Madrid, 1960. Vid. también el inventario de G. Guastavino Gallent, Biblioteca General del Protectorado de España en Marruecos. Inventario provisional de la Sección de Grabados y Cartografía, Tetuán, 1942. En cualquier caso, debemos destacar los grabados de David Roberts, que se han difundido en muchas versiones y copias.

2. Georgius Braun, Civitates Orbis Terrarum, Colonia, 1572. Un comentario sobre esta imagen en J. Bta. VILAR y M.J. VILAR, Limites, fortificaciones y evolución urbana de Ceuta (siglos XV-XX) en su cartografía histórica y fuentes inéditas, Ceuta, 2002, pp. 59-60, si bien aparentemente los autores confunden la imagen del Afrag merinida con las construcciones de Beliunex, ubicadas a muchos kilómetros de la ciudad.

3. J. BeIgBEDER, «Descripciones de Tetuán por los geógrafos de la Edad Media y Moderna», Africa Española, 1914, pp. 383-408; G. GozAlbes Busto, Los moriscos en Marruecos, Granada, 1992; ID., Tetuán, Granada y la frontera del Estrecho, Granada, 2000.
} 
todo su exotismo integrado. Y también, en ese final, es la imagen que enlaza ya de forma muy directa con los grabados recogidos en la guerra de 1860, en especial en la obra de Pedro Antonio de Alarcón ${ }^{4}$.

Tetuán resurgió de sus antiguas fundaciones y destrucciones urbanas hacia 1485-1486, por acción de los guerreros granadinos emigrados con Alí alMandari ${ }^{5}$, se acrecentó más adelante con el gobierno de los Naqsis, y con la emigración de los moriscos, teniendo también notable importancia la etapa de los Banu Riffi, entre finales del siglo XVII y las primeras décadas del siglo XVIII. La importancia de los mudéjares y moriscos en el nacimiento, crecimiento y desarrollo de la ciudad ha sido generalmente bien destacada por parte de un amplio sector de la historiografía ${ }^{6}$.

No obstante, la pulsión entre la concepción del carácter mudéjar o morisco del desarrollo urbano de Tetuán, y la interpretación contraria que reduce ampliamente el papel de los hispanos, se mantiene de forma muy sorda, raramente expresa, en la visión histórica de la ciudad. El abandono de la Historia de Tetuán por parte de los marroquíes, desde 1956 hasta hace bien poco tiempo, ha sido así destacado por parte de Jean-Louis Miège: “on a negligé un peu Tétouan qui a été gouvernée pendant 44 ans par les Espagnols. Ces derniers sont d'ailleurs en posesión d'une importante historiographie qui rattachait toujours Tétouan à l'Ibérie et à son passé Andalous, ce qui était contesté il y a quelques 35 ou 40 ans par les méthodes d'interpretation historique d'alors" ${ }^{\prime 7}$.

En el presente trabajo vamos a intentar ofrecer una aproximación a la respuesta a partir del análisis de dos grabados históricos de Tetuán, publicados en el siglo XVIII. En los inicios del siglo XX la «Mission Scientifique du Maroc», que publicaba Archives Marocaines, en el despliegue de los trabajos sobre ciudades y regiones de Marruecos, encomendó a A. Joly la elaboración del estudio de Tetuán. Los resultados, bastante extensos, de esta publicación a nuestro juicio son muy meritorios, y todavía en el momento actual tienen cierta validez, más

4. En la edición reciente de P.A. DE AlARCón, Diario de un testigo de la guerra de África, edición de M.P. PALOMO, Sevilla, 2005, se han incorporado los grabados originales (si bien en dimensiones más reducidas).

5. G. Gozalbes Busto, Al Mandari el granadino, fundador de Tetuán, Granada, 1988; 2ª ed., Granada, 1993.

6. A. Yebbour Odd, Una ojeada sobre la Historia de Tetuán y sus familias oriundas del Andalus, Tetuán, 1948; T. RuIz DE Cuevas, Apuntes para la Historia de Tetuán, Tetuán, 1951; R. GIL GrimaU, «Profesiones femeninas de origen andalusí en la Historia de Tetuán», Miscelánea de Estudios Árabes y Hebraicos, 28-29 (1989-1990) pp. 69-76. Vinculación muy directa ratificada en los múltiples trabajos de G. GozAlbes Busto, entre ellos «Antroponimia morisca en Marruecos. Datos para su estudio», Congrés Internacional 380 aniversari de l'expulsió dels moriscos, Barcelona, 1994, pp. 351-360; «La antroponimia morisca en Marruecos durante los últimos treinta años», Actes du VI Symposium Internacional d'Etudes Morisques, Zaghouan, 1995, pp. 97-115.

7. J.L. MiÈGE, «Colloque Tétouan au XIX siècle», Revue Maroc Europe. Histoire, Economies, Sociétés, 4 (1993), p. 304. 
allá de los errores, por otra parte lógicos, y de los cambios en las conclusiones por conocimiento de nueva documentación ${ }^{8}$.

Lo que ahora nos interesa es que dicho estudio, aceptando la presencia andalusí primero, y morisca después, por lo general tendía a minusvalorar su peso, en contraposición ciertamente con lo que después iba a destacar la historiografía española. De esta forma, una de las conclusiones principales del estudio de Joly era que la vieja ciudad, de unas dimensiones muy reducidas, ciertamente creció en el siglo XVII (etapa morisca), pero su verdadero despliegue se produjo en la etapa de gobierno de Ahmad al-Riffi y de sus sucesores (1683-1727). Aunque no lo diga expresamente, el autor recoge como fundamento de sus conclusiones, ni mucho menos único, la imagen que aparece en un grabado de un autor danés, Georg Höst, y que considera «une vue intéressante de la ville, ou l'on voit distinctement ses contours et ses remparts» ${ }^{9}$.

Georg Höst publicó su obra en danés en 1781, pero la misma es algo más conocida por la versión alemana que apareció ese mismo año; en realidad, hablando con mayor precisión, su visita a Tetuán y su estancia en Marruecos se produjo en torno a 1765. Se trata, en efecto, de una vista bastante completa del marco urbano de Tetuán, dando también algunos detalles sobre el valle en el que se asienta la ciudad ${ }^{10}$. Por lo demás, en su texto Höst ofrece pocos datos sobre Tetuán, a la que considera "bonita ciudad", y alaba su territorio, limitándose a destacar que sus habitantes eran más civilizados que en otras partes de Marruecos, y que todos, incluso "los moros", saben hablar español. Indicaba que los corsarios llegaban de vez en cuando, pero no permanecían mucho tiempo, y calculaba en unos 14.000 el número de sus habitantes.

La imagen presenta perfectamente algunos detalles excepcionales de una ciudad que, como puede observarse, desciende de las rampas del monte Dersa. Una ciudad además perfectamente amurallada, destacando en su interior los altos minaretes, y sobresaliendo en altura un extenso recinto de la alcazaba. En el interior de la urbe, en su zona central, se detecta un dilatado espacio diáfano. A la luz de esta imagen quedan escasas dudas de que el Tetuán de 1781 era ya muy similar al de 1860, que describe Joly de una forma bastante pormenorizada, y que está representado en el plano de metodología más moderna hecho por los españoles en esa fecha ${ }^{11}$.

El trabajo de Joly, muy utilizado por parte de la historiografía tetuaní, sin embargo fue objeto de controversia en su día con algunos intelectuales españoles

8. A. Joly, «Tétouan», Archives Marocaines, 5 (1905), pp. 199-343 y 6 (1906), pp. 161-264.

9. Ibídem, $2^{a}$ parte, p. 234.

10. Georg Host, Nuchrichten von Marocos und Fez, Copenhague, 1781. La ilustración de Host ha sido reproducida recientemente en M. AKRACHE, J.A. MARTínEZ y L. El-MeshaBI, Fortificaciones en el Norte de Marruecos: Tánger-Tetuán, Murcia, 2005.

11. A. Sierra OchOA, op. cit., fig. 8. 


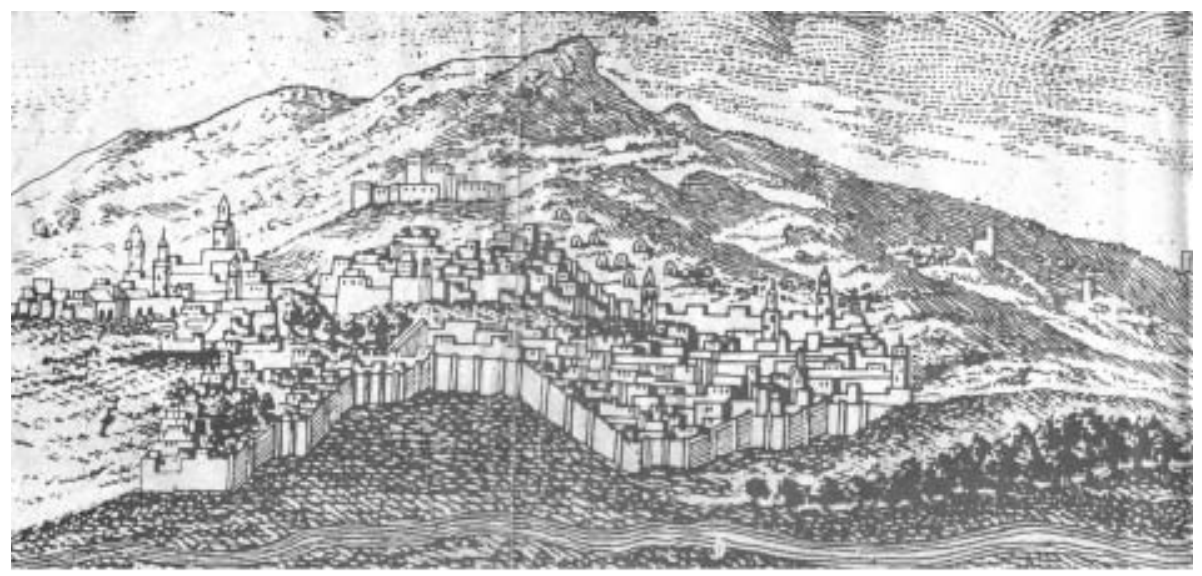

Figura 1. Grabado con la imagen de Tetuán en Georg Höst (1781).

de comienzos de la etapa del Protectorado. En el trabajo de Juan Beigbeder, muy poco conocido, en el que se recogen textos diversos de escritores europeos sobre Tetuán, se hace una fuerte crítica de los grandes errores de Joly, si bien en pocas ocasiones se especifican las referencias concretas. Una de ellas es justamente acerca de esta imagen: "los trabajos de Höst, de los que tanto partido se sacó luego..., tienen de interesante para nosotros el haber publicado un grabado con la vista de Tetuán, grabado que algún autor contemporáneo supuso que era la primera vista ilustrada que se conoce de esta ciudad, cuando es sabido que dicha estampa es copia de la que publicó el viajero inglés Windus"12.

En efecto, la comparación entre el grabado de Höst y el de Windus deja poco lugar a las dudas acerca de que el segundo tuvo ante la vista, no sólo se orientó sino que copió de forma directa el del viajero inglés que le precedió en más de medio siglo. La mayor diferencia se encuentra en el mayor sentido estético del danés, que recoge una representación más bella del espacio urbano, y muy en especial del minarete de las mezquitas, que se muestra mucho más estilizado. No obstante, parece claro que la representación de Windus no sólo le gustó, y la consideró suficiente, sino que más allá de perfeccionar los trazos del dibujo, no estimó necesario introducir cambios significativos. El Tetuán de 1781 no es otro que el Tetuán de 1721, y un grabado técnicamente es una copia del otro, por lo que procede centrar la atención en el más antiguo, aunque no esté dotado de similares valores estéticos.

Esta imagen más antigua conocida de Tetuán es la de ese viajero inglés, John Windus, que en el año 1721 estuvo en Marruecos con motivo de una em-

12. J. BEIGBEDER, op. cit., pp. 403-404. 
bajada para redimir cautivos ${ }^{13}$. Entró en el territorio marroquí por el Norte, y visitó Tetuán antes de emprender el viaje hacia Mequinez. En su libro realiza una muy breve descripción de la ciudad ${ }^{14}$, en la que tan sólo destaca propiamente el palacio del "Basha" y la plaza que se hallaba frente al mismo. Es cierto que Windus alaba mucho las casas de la ciudad y su disposición, así como el tipismo de sus calles ${ }^{15}$.

Presta mucha mayor atención a las actividades de los tetuaníes, así como a la figura del "Basha", señalando que poseía unos magníficos jardines a tres millas de Tetuán, en los que tenía muy buenas plantaciones. En esta época ocupaba el poder en Tetuán la familia de Ali Al-Riffi, a quien el sultán había nombrado gobernador de todo el Norte de Marruecos; en concreto, desde 1713 el "Basha" era el hijo de Alí, de nombre Ahmad" ${ }^{16}$. También era un momento en el que el sultán mimaba a su gobernador tetuaní, ya que se hallaba inmerso en un prolongado proceso de cerco a la plaza española de Ceuta.

La embajada inglesa fue muy bien agasajada por las autoridades tetuaníes, de forma que este hecho se refleja con claridad en el texto. Windus no ofrece muchos datos sobre la ciudad, al contrario que su compatriota Braithwaite que, por las mismas fechas, hizo una magnífica descripción de Tetuán ${ }^{17}$. De hecho, Braithwaite, como todos los viajeros e informantes de la época, destacan el carácter de descendientes de los moriscos españoles de los habitantes de Tetuán ${ }^{18}$, de los que incluso de forma recurrente se indica que todos hablaban el español, aspecto que no merece particularmente la atención de Windus.

En cualquier caso, quizás la mejor aportación de Windus es que recoge ese primer grabado conocido sobre la ciudad de Tetuán. Se trata de un dibujo no sólo de la ciudad sino que lo integra en el valle, visto desde las alturas del Sur,

13. La única reproducción que conocemos, de pésima calidad, aparece en N. ERZINI, «The Architectural Patronage of the Basha Ahmad ar-Rifi in Tetuan and its region», Tétouan au 18ème siècle (1727-1822). Actes du Colloque, Tetuán, 1995, p. 99.

14. John Windus, A Journey to Mequinez, Londres, 1725, p. 11 y ss.

15. Ibídem, pp. 22-23.

16. J.L. MièGE, Tétouan à travers les siècles, Tetuán, 1995, p. 15.

17. J. BRAITHWAITE, The History of the Revolutions in the Empire of Morocco upon the Death of the late Emperor Mulay Ishmael, Londres, 1729, mucho más conocida por la versión francesa, Histoire des revolutions de l'empire de Maroc depuis la mort du dernier empereur Muley Ismail, Amsterdam, 1736.

18. Por ejemplo M. DE SAINT Olon, Relation de l'Empire de Maroc, Paris, 1695, p. 12: "les habitants de Tetouan qu'on fait monter à plus de quinze milles, se disent Andalous, et parlent presque tous espagnol, car tout le monde çait que les maures on esté maîtres de l'Espagne pendant six ou sept cens ans... mais Philippes III, ayant découvert leurs menées les en chasa en 1610. Ils en sortirent au nombre de plus de cent mille de tout sexe et de tout âge, et la plus grande partie se retira en Affrique, et s'établit à Salé et a Tetouan". Es decir, en 1695 se seguía considerando que los habitantes de Tetuán, calculados en las mismas cifras que tuvo la ciudad a todo lo largo del siglo XVIII, eran en su gran mayoría los descendientes de los moriscos expulsos de España. 
al Oeste de La Torreta, en el actual Bu-Semlal. La visión del dibujo abarca desde el extremo occidental de la ciudad hasta el mar, con la desembocadura del río Martín ${ }^{19}$.

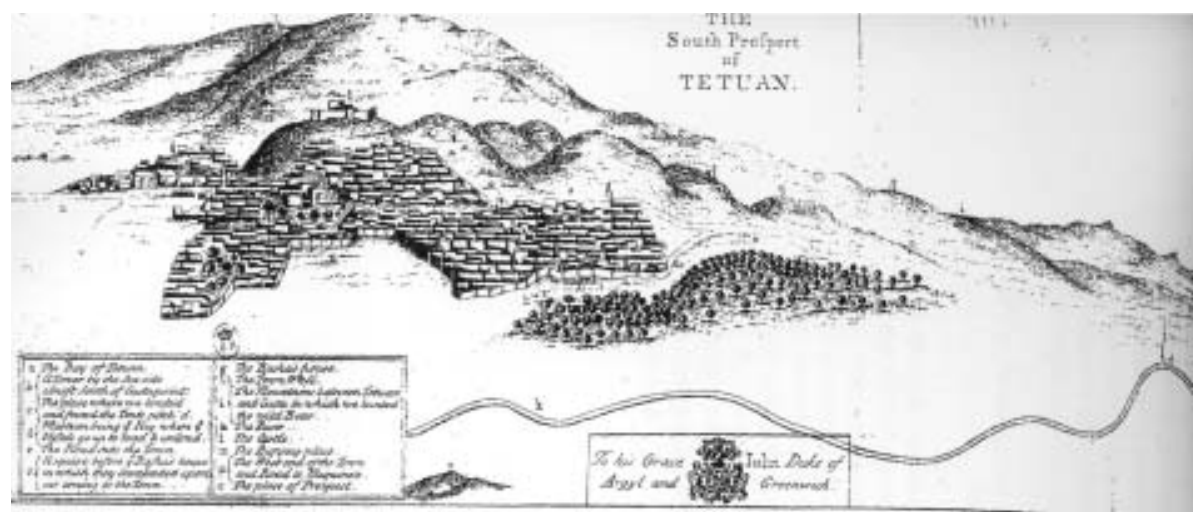

Figura 2. Vista de Tetuán desde el Sur, publicada en 1725 por John Windus.

Así en el dibujo recogido por Windus se observa en primer plano el río Martín serpenteando por el valle, hasta desembocar en el mar junto a lo que parece una pequeña aglomeración de viviendas, más bien tiendas. La posición de las mismas no deja lugar a las dudas, se trata del emplazamiento de Riomartín. Con anterioridad a la desembocadura del río, en la curva de un meandro, se observa la confluencia de una pequeña corriente de agua, y en la lectura anexa se indica que es el refugio de los bajeles de "Marteen".

Este es el que había sido el puerto corsario de Tetuán, que aparece en los documentos de los siglos XVI y XVII. En esta misma época, en 1725, otro inglés de visita en la ciudad, Simon Ockley, afirmaba lo siguiente: "los que vienen para el comercio toman aquí la precaución de descargar sus barcos, al menos en parte, para pasar la barra del río, pero cuando se la ha pasado se encuentra bastante agua como para llegar a una bahía que está a dos millas más arriba, y que se llama Martín, donde los barcos están al abrigo de los vientos" ${ }^{20}$. Igualmente, en el informe del cónsul de Francia en el año 1701 se indicaba que el lugar de refugio de los barcos se encontraba en Martín, a unas $3 / 4$ leguas de la barra en la desembocadura del río ${ }^{21}$.

19. J. WINDUS, op. cit., grabado entre las pp. 22 y 23.

20. Simon OCKLeY, Rélation des Etats de Fez et de Maroc, Paris, 1726, pp. 30-31.

21. J.L. MiÈGe, Tétouan..., pp. 22-23. 
La corriente de agua que aparece, y que en su confluencia con el Martín daba lugar a esta "bahía", es la todavía existente en el siglo XIX, y nombrada como río Alcántara en los episodios de la guerra de 1860. El lugar se corresponde con el posterior puesto de la Aduana ${ }^{22}$. Ni el antiguo río ni la antigua aduana aparecen hoy identificados en la “Carte du Maroc 1/50.000" elaborada en el año 1969.

Al Sudeste de la ciudad se observan unas pequeñas alturas cubiertas de árboles, que señalan un lugar boscoso de posible diversión. Se encuentra al Norte del curso del río, por lo que se trata de una zona urbana en la actualidad, en el descenso hacia el río, y las áreas aledañas a Sania Ramel. Dos líneas de montañas, marcadas por el Yebel Dersa, descienden, teniendo torreones, uno especialmente importante y que, por la perspectiva y situación, debe ser el de Killeli de la guerra de 1860 (aparece representada en grabado en la obra de Pedro Antonio de Alarcón). La línea de montaña finaliza en el mar, con otra torre (en la lectura se indica que mirando a Ceuta), que indudablemente es la existente también en el Cabo Negro.

Por encima de la ciudad, algo separada de ella, se destaca muy bien la alcazaba, que, como otros monumentos, el texto identifica en lectura ${ }^{23}$. Aparece aislada de la propia ciudad, y en este caso no deja de ser curiosa la mayor precisión en el dibujo de Höst. La alcazaba comenzó a construirse en época de Ali Almandari, y finalizada en su estructura principal por sus sucesores ${ }^{24}$. Braithwaite por estas mismas fechas indica que esta alcazaba era muy vieja, y estaba formada por dos cuadrados, pero que las murallas de la misma se encontraban en muy mal estado; igualmente señalaba que la alcazaba estaba batida desde lo alto de montes cercanos, por lo que era de escasa utilidad.

En el grabado de Windus por debajo de la alcazaba, descendiendo de las alturas, aparecen una serie de construcciones con techo en bóveda de medio cañón, y una gran puerta de igual forma; se trata indudablemente de las tumbas granadinas del cementerio musulmán, las de mayores dimensiones aparecen en la parte más alta, que descienden a lo largo de la muralla de la urbe (hasta Bab al-Maqqabar o "puerta de los muertos"). Es evidente que esta puerta, no mencionada de forma expresa en el dibujo ni en las lecturas, es la que

22. Esta Aduana fue construida por orden real en 1757; A. Joly, op. cit., p. 234; T. RUIZ DE CUEVAS, op. cit., p. 28. Sobre la política exterior marroquí en esta época, R. LOURIDO DíAz, Marruecos y el mundo exterior en la segunda mitad del siglo XVIII, Madrid, 1989.

23. El ingeniero militar Joseph Gayoso en 1720 indicaba lo siguiente sobre Tetuán: "en su inmediación y parte mas alta de su circunferencia tiene un castillo antiguo, son sus torres y almenas, que se mantiene en estado"; D. BACAICOA ARNAIZ, «El brigadier-ingeniero Don Joseph Gayoso y el sitio de Ceuta en 1720», Hespéris-tamuda, 2 (1961), p. 267.

24. L. Del Mármol Carvajal, Descripción General de Affrica, Granada, 1573, folio 131 vo: "Tetuán está puesta en un cerro, y en lo más alto tiene un castillejo a la parte del Norte, que llaman Castil de Adives, cercado de tapias de tierra baxas". No cabe duda de que la alcazaba fue fortalecida mucho en el siglo XVII, aunque no es menos cierto que la que se describe a comienzos del siglo XVIII no coincide exactamente con la existente en 1860. 
desde el camino de Ceuta sirve de entrada principal de la ciudad desde el Este. Pero en el grabado se observa la bifurcación del camino, para enlazar con la muralla en el ángulo SE; nos parece indudable que ese camino apunta a Bab l'Uqla (es decir, a la "Puerta de la Reina" de la guerra de 1860, como ha sido siempre conocida por los españoles).

Desde la puerta septentrional, la del cementerio, el dibujo marca muy bien una calle principal y muy recta, que atraviesa longitudinalmente toda la Medina, la antigua fundación de Al-Mandari, hasta desembocar en una gran plaza ${ }^{25}$. En ésta se dibujan algunos árboles, marcando que se trata de un espacio de grandes dimensiones. En la lectura se indica que es "A square before Bashas house", que había destacado mucho en el discurso literario, y al otro lado un gran edificio, que se indica como "The Bashas house". Obviamente este espacio es el de la gran plaza del Feddan, la que sería la Plaza de España en época del Protectorado español ${ }^{26}$, y el palacio califal, construido por Ali al-Riffi ${ }^{27}$, incluso con la representación de la torre de la mezquita del Bacháe ${ }^{28}$. Estos detalles pueden verse mejor en la ampliación que presentamos de la imagen urbana.

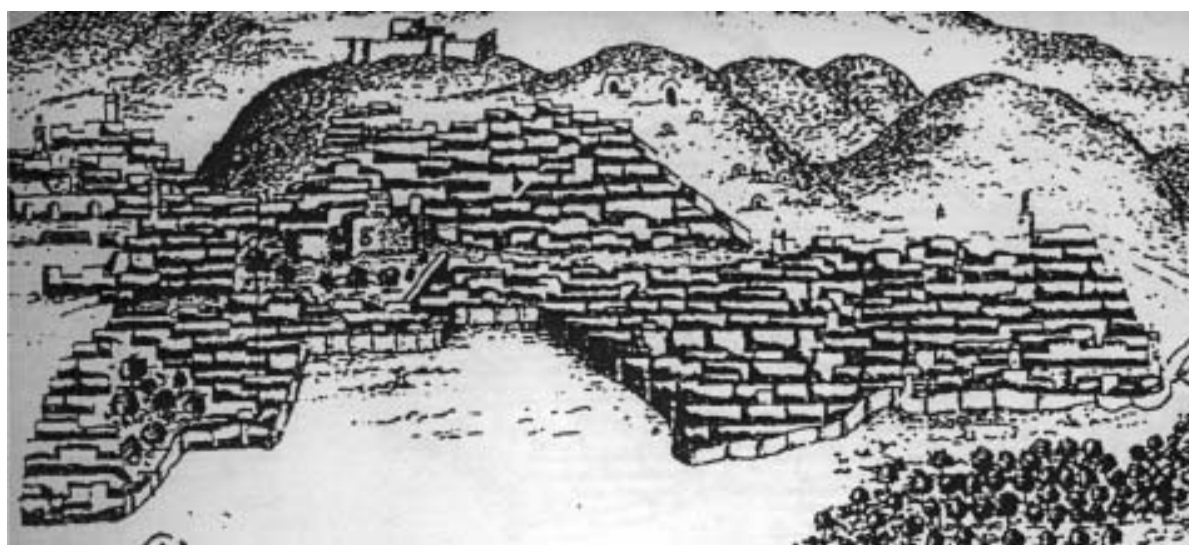

Figura 3. Ampliación de la visión urbana de Tetuán en la obra de Windus.

25. J. BraithWAite, op. cit., p. 165 (trad. francesa) indicaba que "l'attention des maures et des espagnols a se conformer scrupuleseument dans les maisons, les jardins et les habillements. Les maisons son baties en quatrés, ouvertes au sommet, ornées de pilliers qui soutiennent des galeries...".

26. Sobre la plaza del Feddan de Tetuán, vid. A. Joly, op. cit., pp. 300-303.

27. F. VAlderrama MARTíneZ, El palacio califal de Tetuán (su historia y su epigrafía), Tetuán, 1954; ID., Inscripciones árabes de Tetuán, Madrid, 1975, p. 33 y ss.

28. S. SEBASTIÁN, «Las mezquitas de al-Bacha y al-Quebir (Tetuán)», Arte Español, 21 (1977), pp. 4758; A. Sierra OCHOA, «La mezquita del Bajá en Tetuán», Cuadernos de la Biblioteca Española de Tetuán, 16 (1977), pp. 47-58. 
El palacio del gobernador, "Basha House", o el que históricamente conocemos como palacio califal, por lo general se ha considerado una construcción de Ahmad al-Riffi, a partir sobre todo de la descripción que del mismo hace Braithwaite $^{29}$, y que parece todo un recuerdo de la propia Alhambra granadina. Las obras del "Basha", con la ampliación y la decoración del palacio, resultan indudables. Ahora bien, el palacio del alcaide o gobernador, y sobre todo la plantación de los jardines que tanto se pondera, existían ya con bastante anterioridad, como podemos ver en 1682 en el Journal de Voyage de Saint Amant: "el señor embajador fue alojado en la casa del alcaide, que es bastante bonita, ya que dispone de jardines, muchos naranjos, un recibidor, algunas fuentes, y un lugar para tomar los baños, pero no es grande ${ }^{\prime 30}$.

Si observamos en el dibujo de Windus el circuito de murallas y la propia forma urbis podemos detectar, con bastante facilidad, que Tetuán ya estaba formada, a grandes rasgos, tal y como apareció a los ojos de los españoles en 1860. Así, pues, la ciudad había ya rebasado ampliamente hacia el Oeste el espacio del Feddan, con el surgimiento de barrios más allá, en concreto en la zona del barrio y calle Al-Trankat (calle Tranca de los españoles), en lo que Windus llama en dirección al camino de Mequinez. Ese "road to Mequinez" arranca de un punto confuso, pero con toda probabilidad de Bab el Tout, pues de esta puerta de Tánger arrancaba siempre el camino de esta ciudad. En la ampliación, en el extremo SO, puede detectarse otra zona abierta, una especie de plaza, con arbolado, que corresponde con la zona de Al-Masalla, donde se instalaron muchos europeos después de la guerra hispano-marroqui ${ }^{31}$.

Así, pues, el Tetuán que aparece en el dibujo de la obra de John Windus, el de 1721, es muy similar en dimensiones y en estructura al Tetuán que conocieron los españoles tras su entrada en ella en 1860. Queda por saber si este Tetuán de 1721 fue el producto de un crecimiento considerable en fechas muy recientes, o por el contrario, hay que remontar más en el tiempo esa expansión urbana. Como hemos visto, Joly atribuyó el crecimiento de Tetuán a la etapa de gobierno de Ahmad al-Riffi, por tanto, a la etapa de transición entre el siglo XVII y el XVIII.

Quizás a la luz de este grabado pueda postularse que ese aumento de la ciudad, que aparece aquí muy bien consolidado, pudiera ser incluso anterior, quizás más propiamente del periodo de los Naqsis, que aprovecharon muy bien el impulso de los inmigrantes moriscos. No obstante, en el crecimiento urbano de la ciudad vemos que la misma, perfectamente murada, llega hasta el susodicho camino de Mequinez. Podría pensarse que dicho círculo de mu-

29. J. BRAITHWAITE, op. cit., pp. 87-88.

30. Saint Amant, Journal de Voyage (1682), en H. de CASTRIES, Les Sources Inédites de l'Histoire du Maroc, 2 Série. Dinastie Filalienne. Archives de France, II, Paris, 1924, p. 317.

31. A. JOLY, op. cit., p. 292 y ss. 
rallas corresponde con las fortalecidas en el siglo XVIII, en este caso en concreto en los inicios de la centuria, puesto que de no ser así significaría que el crecimiento de la ciudad sería anterior a lo postulado. Sin embargo, en el informe ya citado del ingeniero militar Joseph Gayoso, efectuado en 1720, se indica lo siguiente: "fue en lo antiguo ciudad bien murada; pero hoy se hallan muchos portillos en sus muros que la dejan considerar abierta" ${ }^{32}$.

Así, pues, esas murallas extendidas de Este a Oeste no son las obras de restauración y de establecimiento de nuevas, por el contrario, responden a fechas muy primitivas: "fue en lo antiguo ciudad bien murada". Estos datos indican, con bastante mayor seguridad, que a su vez el Tetuán de 1721 también corresponde, a grandes rasgos, con el de mediados del siglo XVII, es decir, con el Tetuán puramente morisco. Una ciudad es un espacio vivo en la medida en la que es vivido, y naturalmente que existieron cambios entre el Tetuán de 1650, el de 1721 y el de 1860. Pero en su diseño más general, en sus dimensiones y forma urbis, hay bastantes razones para destacar esa continuidad básica de la ciudad morisca durante más de doscientos años.

\section{RESUMEN}

En el presente artículo son analizadas dos imágenes de la ciudad de Tetuán en el siglo XVIII. Igualmente se estudia la tesis del impacto morisco en la conformación urbana.

Palabras clave: Marruecos, Tetuán, moriscos, desarrollo urbano, Edad Moderna.

\section{ABSTRACT}

In the present article two images of the city of Tetuán in XVIII century are analyzed. From those imagenes we study the thesis on the morisco impact in the urban conformation.

Key words: Morocco, Tetuan, moriscos, urban development, Modern Age.

32. D. BACAICOA ARNAIZ, op. cit., p. 267. La situación se arrastraba desde hacía tiempo. En 1701 la Mémoire de J.B. Estelle indicaba que para la toma de Tetuán "no harían falta cañones, puesto que los muros de Tetuán se encuentran en ruinas"; Ph. DE Cossé BRISSAC, SIHM, $2^{a}$ Série. Archives de France, VI, Paris, 1960, p. 237. 